\title{
Research on the Training of Postgraduate Talents Assimilating into the Chinese Traditional Culture
}

\author{
Zhiying Wang ${ }^{1, a}$ \\ ${ }^{1}$ College of Life Science ,Jilin Agricultural University, Changchun, 130118, China
}

Keywords: The traditional culture; Curriculum construction; Construction of teachers'; Cultivation of talents

\begin{abstract}
Chinese traditional culture contains abundant education resources and provides rich culture for graduate students in colleges and universities in the new period of talents training. At present, the Chinese traditional culture education in colleges and universities faces dilemma, and a great loss has arisen, so Chinese excellent traditional culture inheritance should be innovated in colleges and universities graduate student talent training, and university should reconstruct personnel training system from the campus culture construction, curriculum construction, teaching staff construction, guarantee mechanism and carrying out innovation and reform, etc, exploring a new path, in order to further promote the development of graduate student education in colleges and universities.
\end{abstract}

\section{Introduction}

The development of Chinese excellent traditional culture has the development of more than 5000 years, Its content is extensive sprofound and Infinite charm, it is the soul of the Chinese nation, and a variety of cultural concept of continuous development, concise, heritage collection. The ideology and code of conduct of Chinese excellent traditional culture of precipitation formation has been deeply rooted in people's ideology. At the same time it influences and infiltrates into China's social political, economic, cultural and other fields and is the source of the spirit of the Chinese nation prosperous[1].

In the face of global informationization and economic integration of the changed situation, in the face of the conflict moralization and utilitarian 、 the conflict between integrity and individuality 、 the conflict between absoluteness and relativity, relevant departments have to account for the traditional culture in the current graduate education into deep reflection. So in the contemporary complex social environment, the value idea and behavior standard emboding in Chinese excellent traditional culture are advancing with The Times and reflects the flexibility and feasibility. At this point we should attach great importance to the graduate student talent training of into the traditional culture. It includes not only the cultivation of professional knowledge, but also should pay more attention to the graduate student the formation of students' outlook on life, values, world view, and the formation of good moral character and family virtues and so on[2]. Therefore, we want to do the cultivation of the contemporary graduate work well, we should fully absorb and use the essence part of traditional culture, and can use it in talent training flexibly.

\section{The Chinese traditional culture meaning in postgraduate education}

China's traditional education is education of humanism, It's the only purpose of education is how to behave, and it pays attention to teach in virtue and wisdom, not just the pursuit of pure knowledge. It is especially attaches great importance to the moral education and character cultivation, and pays attention to integrity and ethics, and promote vigorous and aspiring, emphasizing the moral sense of responsibility and historic sense of mission, and unify The individual social responsibility and personal moral self-improvement. 
First, the Chinese traditional culture is helpful to improve the graduate student's ideological and moral realm

Chinese traditional culture is an ethic culture, comparison pay attention to the improvement of the people's moral accomplishment and personality. Carrying forward the excellent traditional culture will be helpful for college students to raise their ideological and moral realm[3].

Second, the Chinese traditional culture is helpful to inspire students' patriotic feeling

In Chinese history, it has sprung up millions of epic hero, the national spirit they reflected is encouraging and inspiring. In the current education of colleges and universities, if we can dig and carry forward the patriotic education resources, this will more effectively cultivate college students' patriotic sentiment.

Third, the Chinese traditional culture can help to improve college students' humanities cultivated manners

Today ,utilitarianism and pragmatism is growing, the humanities moral education in college education looks so thin. Identification of national culture and carrying forward the national tradition are the precondition of advocating college humanity spirit. Chinese traditional culture contains rich humanistic spirit, how to mining, absorption and combine with talent training, eventually can improve college students' humanities cultivated manners.

Forth, the Chinese traditional culture is helpful to cultivating graduate students a sound personality the graduate student talent training scheme's persistent spirit with Chinese traditional culture is the personality cultivation, universities should draw lessons from and to bring into full play the advantages of traditional culture in the personality education and modern education contents and methods, cultivates modern citizens with sound personality. Eventually university can help to form the contemporary graduate students correct dealing with people, the relationship between man and nature, man and society and cultivate the students' sound personality[4].

\section{Effective means of graduate student training with the Chinese excellent traditional culture}

First, to strengthen the construction of college excellent traditional campus culture

High quality campus culture can act as "the wind into night, moistens everything silently" for college students. Professional education is for graduate students with the professional education of Chinese excellent traditional culture, we may start from the aspects of the construction of campus culture, for example: The campus infrastructure and architectural style can be added with excellent traditional culture elements, no matter students go to any corner of the campus, they bath in the atmosphere of traditional culture. Campus behavior culture can be riched with a variety of traditional cultural activities as the carrier, exploring the connotations of traditional festivals, actively promoting Chinese excellent traditional culture; playing a role of campus media positive public opinion, Chinese excellent traditional culture such as a variety of channels can widely be publicized through the newspaper, campus network, campus radio, WeChat platform etc., causing the student to achieve "narrative, not learn to" effect[4].

Second, to strengthen the construction of graduate student of Chinese excellent traditional culture courses, implementation of general education on the basis of wide caliber professional training

At present, the Chinese excellent traditional culture content into the graduate program of college humanities courses were rare. Chinese excellent traditional culture is the soul of a nation. As colleges and universities, spreading the excellent traditional culture is a social obligation, traditional culture required courses or elective courses should be brought into the teaching plan according to its circumstance. Philosophy in ancient China, such as classical Chinese literature, Chinese history course can be taught mainly. Colleges and universities can also integrate traditional math teaching in colleges and universities with the "thought morals tutelage and legal foundation", "college Chinese" curriculum integration, etc, for example we can learn from history, society, philosophy, family, personal qualities, the other party to cultivate students moral accomplishment, etc, and we can integrate the essence content and the essence of traditional culture, so we may help students improve the level of personal cultivation and social ethics[5]. 
Third, colleges and universities should strengthen construction of teachers team of Chinese traditional culture

College teachers plays a main role in the graduate student talent training, so, colleges and universities should focus on building excellent traditional culture the teachers troop.

On the one hand, teachers should learn Chinese excellent traditional culture knowledge consciously and constantly update ideas, and are able to have a room for the use of Chinese excellent traditional culture to see and solve the hot issue in today's society, therefore play the basis of the graduate student's education work.

On the other hand, colleges and universities should deal with the excellent traditional culture education training for the teachers. Open teachers' view and improve their cultural literacy through training. At the same time, colleges and universities can pick out a group of elite teachers and ask them to analysis from the perspective of academic interpretation, the Chinese excellent traditional culture, so fuse the Chinese excellent traditional culture into the humanities courses and professional courses to carry on the organic fusion From the perspective of teaching reform.

Forth, to improve college students taking the initiative to accept the consciousness of the Chinese excellent traditional culture

The contemporary graduate student ideas are greatly influenced by the western culture, their understanding of some problems is blurred and lack of discrimination. So, Chinese excellent traditional culture in colleges and universities graduate students in the talent training scheme is urgently needed, it can be done through the following measures: First, colleges and universities and teachers should break the bondage of traditional education concepts, and may implement various forms of joint training, and can introduce relevant experts sit lecture or as a visiting professor, and can consider to other parts of the universities and research institutions signed a cooperation agreement in order to inspire the graduate student's divergent thinking, let them be familiar with charm and essence of the traditional culture of our country, deeply feel the meaning and value of inheriting Chinese excellent traditional culture, so as to realize joint training graduate students[6]. Second, select Chinese classics and historical celebrity allusions to graduate thesis and subject research, during students researching the history of Chinese classic, admiration for literati, let the students consciously accept the baptism of Chinese excellent traditional culture. Third, universities should create environment into the traditional culture of practice teaching and activities. This allows graduate students deeply intuitive understanding to the new situation of the state, society, enhancing the ability to distinguish right from wrong, and let the students find their life value and the right direction[7].

Fifth, establishing a reasonable and effective system security

Build combined with Chinese traditional culture system of graduate cultivation, we should establish a reasonable mechanism to ensure the effectiveness of education. Reasonable and effective system security should include: First, management mechanism. Universities should set up specialized management department and establish a unified leadership of party committees and departments should, in the working mechanisms of various departments to participate, overall planning into the traditional culture education courses, textbooks, teachers construction, etc.Second, evaluation and supervision mechanism. Colleges and universities should make research combined with Chinese traditional culture of the graduate student talent training test evaluation index system and evaluate Teachers' teaching and students' participating in the implementation and supervision on a regular basis.

\section{Conclusion}

Chinese traditional culture is a culture for thousands of years of countless generations and the crystallization of the wisdom of countless ancestors, but also the precious wealth of all mankind. In today's cultural diversity, colleges and universities should innovate in the postgraduate training content and way of traditional culture, in addition to the reform of teaching content and form, also should absorb the educating function of traditional culture, more and more Integrating into the excellent traditional culture factors, give full play to the advantages of excellent traditional culture, 
let the graduate student subtly into the professional education of traditional culture and determine the correct goal and direction in life, deepen to make due contributions to the education of socialism with Chinese characteristics in order to promote the cultural heritage of innovation.

\section{References}

[1] Jinping Xi. The Youth to Consciously Practice the Socialist Core Values-Symposium Speech Between Teachers and Students in Beijing University [N]. The People's Daily,2014-05-05. [2] Xue Zhu. The study of contemporary value of Chinese traditional culture[D]. Xihua university, master's degree thesis, 2013:5.

[3] Gongkui Liu. The disadvantages of graduate student training mode and the reform of our country[J].Journal of Changchun university of technology,2009,(6):79-83.

[4] Yuepeng Sun, Ting Li. Excellent Traditional Culture in Ideological and Political Education Value in the Implementation of the Strategy [J]. Science and Technology in Western China,2014(1):3.

[5] Li-xia Zou. Theory of the Chinese Nation Outstanding Traditional Culture and the Combination of Ideological and Political Education [J]. The Exam Week,2014(4):4.

[6] Yang Li, Ting Liang. Excellent Traditional Culture into the Ideological and Political Education [J]. In the West of the New,2014(3):2.

[7]Hong-yan Wang, Zongling Zhao. The value of traditional culture in ideological education in colleges and universities. Shanxi higher school journal of social science,2014(2). 